\title{
Diferenças conceituais sobre termos e definições e implicações na organização da linguagem documentária
}

\author{
Marilda Lopez Ginez de Lara \\ Doutorado em ciências da comunicação. \\ Universidade de São Paulo, USP \\ E-mail: larama@usp.br
}

\section{Resumo}

A definição é um instrumento importante na elaboração de uma linguagem de organização da informação, porém nem sempre ela pode ser desenhada segundo os moldes prescritos pelas normas terminológicas. Propomo-nos a reunir alguns elementos para compreender o que é uma definição, como ela é elaborada segundo diferentes pontos de partida e objetivos, quais as dificuldades encontradas na utilização das prescrições da terminologia clássica e das normas terminológicas no tratamento dos discursos das humanidades e das áreas em formação ou transformação, e que alternativas são apontadas para seu enfrentamento. Parte-se do princípio de que, se a transferência da informação ocorre no universo da linguagem, é necessário observar as diferentes tipologias discursivas e sua terminologia, sob pena de comprometer a comunicação em ambientes informacionais.

\section{Palavras-chave}

Definição; Terminologia; Linguagem documentária; Organização da informação; Linguagem de organização da informação.

\section{Conceptual differences on terms and definitions and implications to the documentary language}

\begin{abstract}
Definition is an important tool for document language construction, but in some cases, it is very difficult to use the prescriptions of the international terminological standards. In this article, the purpose is to gather together some elements to understand what a definition is, how it is built according to different points of view, which are the difficulties underlying the classical terminological literature or terminological standards prescriptions taking into consideration the peculiarities of human discourses or in regard to information or transformation areas, alternatives which are proposed. It is presumed that information transfer occurs in the language universe, so that it is necessary to study the different discursive typologies and its terminology to avoid communication problems in the information environments.
\end{abstract}

\section{Keywords}

Definition; Terminology; Documentary language; Information organization; Information organization language.

\author{
INTRODUÇÃO
}

A organização da informação via linguagem documentária tem sua importância aumentada contemporaneamente, quando se deseja contar com mecanismos que desempenhem o papel de filtros para a recuperação, dado o grande volume de informações recuperadas na Internet. A linguagem documentária, entretanto, para exercer esse papel, não pode ser formulada de modo aleatório. É por essa razão que a lingüística documentária*, subdomínio da ciência da informação (CI), cujo objetivo de propor códigos para o tratamento e a recuperação da informação, recorre à terminologia, visando a garantir referenciais para a organização de campos temático-funcionais. A terminologia, por sua vez, não oferece à CI apenas conjuntos de termos relativos a determinadas áreas de especialidade ou de atividade, mas referenciais metodológicos para sustentar a estruturação dos campos lógico-semânticos das linguagens documentárias, desempenhando, assim, um papel complementar à norma documentária de elaboração de tesauros (ISO 2788:1986).

Um dos instrumentos fundamentais para tal estruturação é a definição, que permite, dentre as inúmeras possibilidades de organização, a determinação do campo de interpretação do termo e sua inserção em um campo temático. Para que isso fique mais claro, recorremos a um exemplo. Diante dos termos "casado", "solteiro", "viúvo", "separado", "divorciado", a constituição dos grupos casados e não-casados altera-se substancialmente conforme varia a definição de casamento tomada como ponto de partida. Vejamos:

Casamento: evento relativo à união legal entre pessoas de sexo diferente. No Brasil, a legalidade da união é estabelecida no casamento civil, ou religioso com efeito civil, sendo que o indivíduo só poderá casar legalmente se o seu estado civil for solteiro, viúvo ou divorciado. Os casamentos têm como fonte principal as informações

\footnotetext{
* A lingüística documentária é uma área de estudos interdisciplinar que congrega conceitos da lingüística estrutural, da lingüística gerativa, das teorias do discurso, da semântica, das ciências da comunicação e das tecnologias inteligentes, conforme proposta inicial de Gutiérrez (Gutiérrez, G. J., 1990).
} 
dos cartórios de registro civil. (Fundação Seade) http:// www.seade.gov.br/cgi-bin/lingcv98/spd 01.ksh

Segundo a definição acima, poderemos agrupar em casados, os termos "casado", "separado" e, em "não-casados", "viúvo", "solteiro", "divorciado", supondo que a agregação é sustentada pela definição legal de casamento. Se, entretanto, a definição tomada for baseada nos costumes, e não na lei, o termo "separado" seria agrupado junto com os "nãocasados", reorganizando-se a hierarquia (Lara, 1993).

Vemos, portanto, que a definição desempenha papel crucial na organização dos termos, afetando a estruturação do campo nocional das linguagens documentárias. Nem sempre, porém, podemos contar com definições claras, seja pela ausência de dicionários técnicos que auxiliem o trabalho de organização das linguagens, seja pela dificuldade de delimitação dos conceitos ou noções. Esse último aspecto explica, por exemplo, o fato de que a tarefa de organização de termos nas áreas das humanidades seja mais complexa. Em face desses problemas, é vital conhecer os fatores envolvidos no processo definicional, bem como suas conseqüências para o tratamento da informação.

\section{O termo e o objeto}

O trabalho terminológico de definição tem no conceito seu ponto de partida. Segundo as normas terminológicas, o conceito é uma unidade abstrata criada a partir de uma combinação única de características. Os conceitos são representados pelos termos, que são designações verbais. $\mathrm{O}$ termo é considerado a unidade mínima da terminologia (ISO 704; ISO 1087-1). Mais especificamente, o termo é uma designação que corresponde a um conceito em uma linguagem de especialidade. É um signo lingüístico que difere da palavra, unidade da língua geral, por ser qualificado no interior de um discurso de especialidade. Uma palavra tem propriedades (como em um dicionário de língua), mas tem muitos significados, porquanto são elementos do léxico da língua. Um termo, ao contrário, é uma palavra contextualizada no discurso, tendo, conseqüentemente, um referente de interpretação. Le Guern sugere que a palavra, unidade do léxico, constitui um predicado livre, e o termo, enquanto unidade do discurso, um predicado vinculado (Le Guern, 1989). Dito de outro modo, a palavra no discurso - o termo - associase a uma classe de objetos, às coisas do mundo real, tendo, dessa forma, uma extensão.

A literatura terminológica clássica privilegia o conceito de objeto afirmando que essa noção é fundamental em terminologia porque permite realizar a distinção entre trabalho terminológico e trabalho lingüístico. Se na lingüística não há primazia do significado sobre o significante, na terminologia a forma significante não é fundamental: há primazia do conceito sobre a forma.

Para a lingüística, o importante é a pergunta "o que significa” - que remete ao uso que faço da palavra; já para a terminologia, interessa a relação da palavra com o que está fora da linguagem - "o que é" (Dubuc, 1977; Rondeau, 1984). Trata-se de perspectivas diferentes, já que se pode abordar a palavra como unidade do léxico da língua - e este é um trabalho feito pela lexicografia ao repertoriar todos os sentidos de uma palavra para elaborar dicionários de língua -, ou abordar a palavra como unidade que dá nome a um conceito de especialidade, como faz a terminologia para elaborar glossários e dicionários técnicos, por exemplo. Dito de outra forma, no trabalho lexicográfico, o interesse é voltado às propriedades da palavra; na atividade terminológica, às propriedades do objeto dentro de um campo do saber ou de atividade. Isso explica o privilégio da lógica para a organização das terminologias, por meio da identificação das relações entre as propriedades do objeto.

Além das diferenças relacionadas à função da lexicografia e da terminologia, é preciso notar que a terminologia clássica nascida de Wüster considera primeiramente o conceito, atribuindo à língua apenas a função designacional. Como conseqüência, não observa a prioridade da linguagem enquanto instrumento de comunicação. Todavia, para a lingüística estrutural, a função referencial da língua é a menos importante, mas é ela que é enfatizada pela terminologia clássica. Sublinhando a função referencial da língua, tal terminologia pretende enfatizar a referência, ou o elemento que está fora da língua.

A ênfase no elemento extralingüístico se dissolve, entretanto, se substituirmos 'referência' por 'contexto'. Passa-se a abordar as 'propriedades do objeto' por meio da palavra, não privilegiando sua materialidade física, mas a resultante cultural construída em função de determinados objetivos. De fato, a realidade na relação linguagem/pensamento não pode ser vista como mero reflexo passivo ou reprodução. A especificação e o valor dos objetos e a nossa interação com estes objetos decorrem do universo lingüístico ao qual pertencemos. "Só podemos tomar consciência dessas relações na medida em que elas significam, e elas significam apenas por meio da linguagem" (Baccega, 1995). O entendimento do mundo como um conjunto de objetos exteriores "só existe enquanto atividade humana sensível e é apreendida 
necessariamente de modo subjetivo. Portanto a linguagem fornece o meio e o motivo para se passar do mundo das idéias para o mundo real... É a realidade imediata do pensamento .... e é também realidade simbólica, razão pela qual corre o risco de se apresentar com uma determinada autonomia” (Tálamo, citada por Baccega, 1995).

A partir dessa perspectiva, podemos afirmar que a distinção entre palavra e termo qualifica este último como uma expressão lingüística no interior de um discurso de um domínio de especialidade, mas nunca fora da linguagem. Essa abordagem altera significativamente a forma de enfrentar os termos e suas definições.

\section{A definição}

A referência dos termos na terminologia é formulada mediante uma operação de definição. Uma definição é um enunciado que descreve um conceito permitindo diferenciá-lo de outros conceitos associados, podendo ser formulada de duas maneiras básicas: definição por compreensão (ou por intensão), ou ainda, definição intensional, que compreende a menção ao conceito genérico mais próximo (o conceito superordenado) - já definido ou supostamente conhecido - e às características distintivas que delimitam o conceito a ser definido; e definição por extensão ou extensional, que descreve o conceito pela enumeração exaustiva dos conceitos aos quais se aplica (conceitos subordinados), que correspondem a um critério de divisão (ISO 1087-1). Essa mesma concepção está presente na ISO 704, que caracteriza uma definição como uma unidade com intensão e extensão únicas (ISO 704).

Exemplo:

- definição intensional

Lâmpada incandescente: lâmpada elétrica cujo filamento é aquecido por uma corrente elétrica de tal modo que ela emite luz (ISO 1087-1:2000)*.

\section{- definição extensional}

Gases nobres: hélio, neônio, argônio, criptônio, xenônio e radônio (ISO 1087-1:2000).

É curioso observar, entretanto, que a proposta de definição das normas terminológicas não é obedecida nem mesmo no interior dessas mesmas normas. A ISO 704 e a ISO 1087-1 propõem apenas as definições do tipo intensional e extensional (a primeira, baseada em relações hierárquicas, e a segunda, pela enumeração dos conceitos subordinados). As definições de objeto,

\footnotetext{
* Tradução livre. Norma original em inglês e francês.
}

conceito, definição e designação na ISO 1087 não obedecem às formas prescritas (Pozzi, 2000), como se observa no exemplo abaixo:

object: anything perceivable or conceivable/tout ce qui peut être perçu ou conçu

De fato, os dois modelos de definição são aplicáveis quando trabalhamos com objetos bem determinados, próprios das ciências e técnicas, o que não acontece necessariamente com os discursos das humanidades, como já assinalamos, ou das áreas em formação ou transformação. Os modelos de definição intensional ou extensional são úteis à ciência da informação na elaboração de linguagens documentárias quando o universo tratado comporta a identificação clara de objetos. Tais formas definicionais estão subjacentes à identificação dos descritores quando a operação de sua circunscrição remete simultaneamente ao TG (termo geral) e aos TEs (termos específicos), seja nas relações genéricas (gênero/espécie) ou nas partitivas (todo/parte), que correspondem, do ponto de vista estritamente lingüístico, às relações hierárquicas de hiperonímia/hiponímia (Lyons, 1977). As conjunções e disjunções entre os termos dependem de um ponto de partida, de uma perspectiva, ou dito de outro modo, de uma hipótese de organização.

A visão de Sager corrobora a perspectiva acima, ao admitir que a definição é uma explanação aceita do significado especializado de itens lexicais cuja ocorrência pode ser documentada em várias fontes (Sager, 1990). Ela fixa a intensão do termo, mas a precisão com que ela vai realizar essa fixação varia do extremo rigor à flexibilidade. Sager critica a teoria terminológica clássica pelo fato de ela reconhecer apenas a definição analítica (aquela possivel pela hierarquia) e propõe considerar a definição como um processo que utiliza vários métodos, salientando que poucas definições seguem o padrão clássico "gênero e diferença". Além dessa definição (definição por análise) ou analítica, o autor considera que o processo definicional pode ser feito por sinonímia, por paráfrase, por síntese, por implicação (usando a palavra em um contexto explicativo), por denotação (que é a definição por extensão ou enumeração, admitida pela teoria clássica), por demonstração (a definição ostensiva), além das definições que combinam vários dos tipos anteriores.

De qualquer modo, uma definição não é única, mas varia conforme a fonte, razão pela qual Dahlberg diz que fazer uma definição equivale a estabelecer uma 'equação de sentido', limitá-lo de algum modo, para fixar os limites de um conceito ou idéia (Dahlberg, 1978). 


\section{Definição terminológica e definição lexicográfica}

Admitindo uma diferença entre o termo e a palavra, podemos distinguir entre a definição terminológica e a definição lexicográfica. Para a elaboração das linguagens documentárias, a definição terminológica é preferida à lexicográfica porque delimita o universo focalizado: a primeira é utilizada pelos dicionários de especialidade; a segunda é própria dos dicionários de língua geral.

A definição terminológica (ou terminográfica) descreve, delimita e distingue os conceitos e também concorda com a concepção wüsteriana de unidade terminológica enquanto "símbolo convencional que representa uma noção definida num certo domínio fundador" (Wüster, citado por Desmet, 1990, p. 6). Como a definição aristotélica, a definição terminológica implica a demarcação de um limite.

As terminologias seriam, desse modo, sistemas definicionais que refletem a organização estruturada e delimitada de domínios específicos. A definição terminológica é classificadora, hierarquizante, estruturante; relaciona-se à definição da coisa, ao contrário da definição lexicográfica que se relaciona à palavra e é feita pela identificação de traços semânticos que caracterizam o significado. $\mathrm{O}$ significado é lingüístico; o conceito é terminológico.

A definição terminológica busca definir o conceito, e não um significado, estabelecendo um jogo de conceito a conceito que determina as relações que os unem. A unidade de sentido visada na definição terminológica é o conceito ou noção, que difere substancialmente do significado. O significado mantém um laço de indissociabilidade com o significante. $\mathrm{O}$ conceito, não, é uma unidade muito mais livre (Desmet, 1990) que se delimita no domínio.

A definição terminológica liga-se à definição aristotélica: "a definição é uma proposição que exprime o que a palavra significa (...) A palavra é signo da proposição (...) A definição e a significação de uma palavra não podem ser dadas por uma outra palavra, mas somente pela proposição" (Aristóteles Segundas Analíticas, citado por Desmet, 1990). ... A definição da palavra explica o que ela é na língua: a definição da coisa é "uma relação entre uma idéia (o definiendum) e outras idéias (o definiens)" (idem, ibidem).

Na ótica de Desmet (na linha da terminologia wüsteriana), o processo definicional parte do conceito para chegar ao termo, o que caracteriza um procedimento onomasiológico. As propriedades semânticas do conceito seriam como os predicados da lógica, e os conceitos inteiros, conjuntos coerentes de juízos sobre o objeto, refletindo suas características. A definição terminológica inclui a definição genérica e a partitiva, bem como a definição funcional (Desmet, 1990).

Dahlberg distingue entre a definição real e a definição nominal, que se assemelham à definição terminológica e à definição lexicográfica discutidas por Desmet. A definição real procura delimitar a intensão de um conceito, e a definição nominal, fixar o sentido de uma palavra. A definição real relaciona-se com o conhecimento do objeto, apresentando "o conhecimento contido em determinado conceito" (Dahlberg, 1978). Já a definição nominal "procura fixar o uso de determinada palavra" (idem, ibidem).

A diferença entre a definição terminológica e a definição lexicográfica remete, portanto, a perspectivas distintas de abordagem, muito embora elas não sejam isentas: a lexicografia parte do signo para chegar à determinação do conceito (procedimento semasiológico); a terminografia parte da noção (ou conceito) e pesquisa os termos que lhe correspondem (procedimento onomasiológico)

\section{A dificuldade para a definição de termos relativos a objetos indeterminados}

Para a terminologia clássica, o termo é o produto de uma relação extralingüística que parte do objeto e é mediada pelo conceito. A operação de definição circunscreve o objeto em relação a outros no mesmo domínio (ou domínios correlatos). A abordagem extralingüistica põe em evidência a aceitação da dicotomia sujeito/objeto. Entretanto, pode-se verificar que há termos que não têm objeto, ou, pelo menos, cujo objeto é relativamente indeterminado. A ausência desse objeto dificultaria, pois, a elaboração de uma definição referencial. Não é sem motivo a dificuldade encontrada para elaborar definições de conceitos das humanidades ou das áreas em gestação, problema que se rebate na construção das linguagens documentárias.

Sobre esse aspecto, Hermans distingue dois tipos de termos no vocabulário científico: os termos técnicos e os termos teóricos. Os termos técnicos são utilizados para designar observações, medidas, experiências, instrumentos, ou seja, para falar de objetos logicamente preexistentes aos termos. A decupagem do campo nocional de um domínio técnico parte desses objetos e de suas noções, atribuindo-lhes termos. $O$ termo não é definido a partir de seu funcionamento no discurso, de sua significação na sua polissemia eventual, mas corresponde a uma noção particular dentro do campo nocional. Já os termos teóricos "não se relacionam às noções preexistentes ou a representações mentais de 
objetos concretos ou abstratos. Ao contrário, eles são utilizados com uma ou várias significações. Sua significação depende de seu funcionamento no contexto... Um termo teórico deve ser estudado e definido no seu ambiente e segundo os paradigmas nos quais figura. Sua significação depende de relações que ele mantém com os outros termos do enunciado, que o delimitam, e relações privilegiadas entre certos termos em um enunciado ou disciplina dada. Um conceito tem, então, simplesmente, a significação de um termo. Não é possível, conseqüentemente, construir uma árvore nocional de seus conceitos para estruturar previamente um domínio" (Hermans, 1995).

A visão do autor é importante para compreender que a significação dos termos teóricos (ou científicos) é continuamente gerada pelo uso que os cientistas fazem dos termos. No processo de pesquisa podem ser gerados termos imprecisos, não exatamente por uma incapacidade de precisão, mas porque isso reflete a própria instabilidade e movimento das ciências. "A estabilidade, nas ciências, equivale à estagnação" (idem, ibidem). Os termos na área científica refletem uma instabilidade que é próxima do equilíbrio entre determinação e indeterminação. Quando os conceitos científicos são muito determinados, eles deixam de funcionar como instrumentos de descoberta ou de explicação (idem, ibidem).

Contrariamente aos conceitos técnicos que têm objetos bem determinados, os conceitos teóricos são indeterminados. "A precisão é obtida sacrificando-se sua significação. E é graças a seu caráter metafórico e conotado que esses termos teóricos funcionam como elementos heurísticos e explicativos dentro da atividade científica" (idem, ibidem).

Essa indeterminação identificada por Hermans também caracteriza os discursos contemporâneos da ciência de um modo geral. Teóricos como Rorty e Boaventura Santos têm colocado sob suspeita a exclusividade do modelo moderno de ciência, o qual, postulando a necessidade de uma separação rígida entre sujeito/objeto, não se adequaria às ciências humanas, em que o sujeito também é parte do objeto (Rorty, 1988; Santos, 1989). O modelo contemporâneo, ao contrário, procura, via hermenêutica, transformar o objeto distante e incomensurável em um objeto mais próximo e familiar, atenuando as distâncias entre o discurso do senso comum e o discurso da ciência a partir da matriz moderna. Como afirma Boaventura Santos, o discurso da ciência contemporânea recorre, com maior freqüência, à analogia, à metáfora, considera a positividade dos erros, a importância da inferência e até da irracionalidade e também relativiza as distinções entre a linguagem da ciência e a linguagem vulgar (Santos, 1989). Por essa via, compreende-se melhor a afirmação de Hermans de que "várias significações de um termo coexistem dentro de uma mesma disciplina científica" (Hermans, 1995), razão pela qual nem sempre é possível aplicar rigidamente as normas definicionais clássicas.

Os limites da terminologia clássica e das normas terminológicas nascidas a partir de seus princípios têm origem nos propósitos da Teoria Geral da Terminologia (TGT). O objetivo de Wüster, fundador da TGT, era, via normalização, alcançar a precisão e possibilitar a comunicação profissional sem ambigüidades. Sua posição, à época (década de 30), alinhava-se à corrente da filosofia analítica marcada pelo neopositivismo, que considerava a linguagem comum impura e imprópria à ciência. Acreditava-se na homogeneideade do conhecimento científico e na possibilidade de reconstrução lógica da linguagem, ou, dito de outro modo, considerava-se a possibilidade de uma linguagem universal. Embora a lingüística estivesse entre as disciplinas que constituiriam o campo da terminologia, a visão de Wüster sobre a linguagem se restringia à função denominativa. Wüster não via na linguagem a função primordial de comunicação. Considerando, ainda, que os trabalhos do terminólogo vienense estavam mais voltados à engenharia, compreendem-se melhor os limites de sua aplicabilidade.

Em síntese, podemos afirmar que a abordagem onomasiológica é útil apenas quando temos um sistema conceitual estável e coerente no qual às noções correspondem objetos determinados, ou, dito de outro modo, aos termos técnicos. A definição dos termos teóricos seria semasiológica, porquanto sua significação depende de seu funcionamento nos textos. "A definição de termos teóricos consistirá na especificação das diferentes significações que podem ter esses termos (especificações cronológicas, por escola de pensamento, por substrato teórico no qual o termo aparece), de seu valor heurístico, de seu caráter metafórico e eventual, suas conotações, de sua polissemia e da economia lingüistica que lhes conferem essas características" (Hermans, 1995). Toda definição teórica é uma proposta assente na aceitação de uma teoria, mas "as teorias são notoriamente discutíveis. Disso resulta que uma definição é substituída por outra à medida que nosso conhecimento e compreensão teóricos aumentam" (Copi, 1978).

\section{Considerações finais}

As normas terminológicas não pressupõem a distinção entre termos técnicos e termos teóricos, tratando a todos como se fossem termos técnicos, o que se explica em grande parte pela origem da ISO e pelos princípios 
positivos à sua base. A terminologia mais contemporânea tem relativizado a distinção entre palavra e termo (Gaudin, 1995; Cabré, 2000) e, embora essa perspectiva não seja visível nas normas, observa-se que elas tendem a apresentar relativa flexibilização. Comprova o que afirmamos, por exemplo, a menção, na norma ISO 1087-1, aos termos 'termo privilegiado', 'termo tolerado' e 'termo desaconselhado', de certo modo incompatíveis com o que prega a terminologia clássica e prescritiva.

A terminologia clássica é mais onomasiológica, correspondendo, segundo Béjoint, a uma terminologia da denominação. A terminologia onomasiológica é "ancorada na referência”, colocando em jogo uma semântica extensional que tende a se "conformar ao princípio humboldiano (biunívoco) ... segundo o qual uma só forma deve corresponder a um só sentido e viceversa" (Béjoint, 1989). Béjoint bem observa que, na realidade, o trabalho terminológico combina os procedimentos onomasiológico e semasiológicos: primeiro, porque a exploração é circunscrita a um domínio; segundo, porque, se as formas são geralmente extraídas do discurso, seus sentidos não são diretamente extraídos de seus comportamentos discursivos. Não haveria, portanto, solução de continuidade entre o termo e a palavra (o que não quer dizer que não se possa distingui-los), além do fato de que "todo termo, a partir do momento em que se insere nos discursos diferentes dos discursos 'fundadores' que o definem, é susceptível de se 'desterminologizar" (Béjoint, 1989).

Para a ciência da informação, ou mais precisamente, para a lingüística documentária, as discussões sobre a definição colocam em relevo a necessidade de delinear procedimentos que observem as variedades das manifestações discursivas, sem pressupor que todos os discursos sigam o modelo clássico das ciências. Como observa Krieger, as novas áreas científicas e tecnológicas, como também as humanidades e ciências aplicadas, têm sua terminologia distante daquelas das ciências de natureza taxionômica, confundindo-se muitas vezes com o léxico comum da língua, fato que é confirmado pelo crescimento dos sentidos terminológicos nos verbetes dos dicionários de língua comum (Krieger, 2001).

Caso se concorde que a transferência da informação se dá no universo da linguagem, a definição que orienta a construção das linguagens documentárias não pode ser observada sem considerar a diversidade da tipologia dos discursos, sob pena de comprometer a comunicação em sistemas documentários.

Artigo recebido em 26-07-2004 e aceito para publicação de 18 a $21 / 10 / 2004$.

\section{REFERENCIAS}

BACCEGA, M. A. Palavra e discurso: história e literatura. São Paulo : Ática, 1995.

BÉJOINT, H.. À propos de la monosémie en terminologie. Meta, v. 34, n.3, p. 405-411, 1989.

CABRÉ, M. T. Terminologie et linguistique: la théorie des portes. Terminologies Nouvelles, n. 21, p. 10-15, 2000.

COPI, I. M. Introdução à lógica. São Paulo : Mestre Jou, 1978.

DAHLBERG, I. Teoria do conceito. Ciência da Informação, Rio de Janeiro, v. 7, n. 2, p. 101-107, 1978.

DESMET, I. Questões de semântica em terminologia: a problemática da definição terminológica. Terminologias, n. 2, p. 4-21, dez. 1990.

DUBUC, R. Qu'est-ce que la terminologie? Le banque des mots, Paris, n. 13, p. 3-14, 1977.

FUNDAÇÃO SEADE. Informações sobre os municípios paulistas. Disponível em: <http://www.seade.gov.br/cgi-bin/lingcv98/spd_01.ksh>. Acesso em: 16 maio 2004

GUTIÉRREZ, A. G. Estructura linguística de la documentación: teoría y método. Mujrcia : Universidad de Murcia, 1990.

GAUDIN, F. Champs, clôtures et domaines; des langues de spécialités à la culture scientifique. Meta, v. 40, n. 2, p. 229-237, 1995.

HERMANS, A.. Sociologie des discours scientifiques: quelques réflexions. Meta, v. 40, n. 2, p. 224-228, 1995.

INTERNATIONAL ORGANIZATION FOR STANDARDIZATION. British standard guide to establishment and development of monolingual thesauri: 2788. London : BSI, 1986.

Principles and methods of terminology: 704. 2. ed. [S. 1. : s. n.], 2000. Terminology work - principles and methods: 1087-1. Part 1: theory and application $=$ Travaux terminologiques - vocabulaire Partie 1 : théorie et application. [S. 1. : s. n.], 2000.

KRIEGER, M. G.. Terminologia revisitada. In: KRIEGER, M. G.; MACIEL, A. M. B. Temas de terminologia. Porto Alegre : Editora da UFRGS; São Paulo : Humanitas/USP, 2001. p. 47-61.

LARA, M. L. G. de. A representação documentária: em jogo a significação. 1993. Dissertação (Mestrado) - Escola de Comunicação e Arte, Universidade de São Paulo, São Paulo, 1993.

. Representação e linguagens documentárias: bases teóricometodológicas. 1999. Tese (Doutorado) - ECA, USP, São Paulo, 1999.

LE GUERN, M.. Sur les relations entre terminologie et lexique. Meta, v. 34, n. 3, p. 340-343, 1989.

LYONS, J. Semântica. Lisboa : Presença; Martins Fontes, 1977. v. 1.

POZZI, M. ISO 704 e ISO 1087-1: dos normas del ISO/TC37 en conflicto. In: CORREIA, M. (Org.). SIMPÓSIO IBERO-AMERICANO DE TERMINOLOGIA, 2000, Lisboa. Terminologia e indústria da língua. Actas... Lisboa : ILTEC; União Latina; Fundação Calouste Gulbenkian, 2003. p. 831-840.

RONDEAU, G.. Introduction à la terminologie. 2. ed. Québec : Gaëtan Morin, 1984.

RORTY, R.. A filosofia e o espelho da natureza. Lisboa : Dom Quixote, 1988.

SAGER, J. C. A practical course in terminology processing. Amsterdam/ Philadelphia : John Benjamins, 1990.

SANTOS, B. S. Introdução a uma ciência pós-moderna. Rio de Janeiro : Graal, 1989. 